\title{
Comportamento de compra no pequeno varejo: consumo hedônico e utilitário
}

\author{
Buying behavior in the small retail: hedonic and \\ utilitarian consumption
}

\author{
Felipe Gerhard Paula Sousa ${ }^{1}$ \\ Lucas Lopes Ferreira de Souza ${ }^{2}$ \\ Verónica Peñaloza ${ }^{3}$ \\ Marcos Alexander Brasil Ferreira ${ }^{4}$
}

\section{Resumo}

O desempenho de um estabelecimento varejista é influenciado, em grande parte, por fatores capazes de desenvolver um papel racional no processo decisório de seus clientes. Contudo, diversos estudos em pequenos varejos relacionam o comportamento do consumidor nesses ambientes ao caráter de compra hedônico. Nesse sentido, com o intuito de ampliar a compreensão sobre as experiências do consumidor em pequenos varejos, o presente trabalho tem como objetivo analisar o comportamento de compra dos consumidores pautando-se nas dimensões de consumo hedônico e utilitário no pequeno varejo. Ademais, o estudo também objetiva perquirir as principais razões pelas quais os clientes frequentam um pequeno varejo. Para alcançar o objetivo proposto, foi realizada uma pesquisa descritiva, de natureza quantitativa, viabilizada por meio da aplicação de um survey e uso de análise fatorial exploratória. Os resultados revelaram que não prescinde atender tanto as necessidades utilitárias quanto hedônicas dos clientes, pois ambos os valores de compra estão fortemente presentes na ação de compra dos consumidores. Além disso, constatou-se que o atendimento pode transcender a simples utilidade funcional e ampliar sobremaneira a experiência de compra do consumidor.

Palavras-chave: Pequeno Varejo. Consumo Hedônico. Consumo Utilitário.

1 Mestrando em Administração de Empresas. Universidade Estadual do Ceará. Av. Silas Munguba, 1700, Campus do Itaperi, Fortaleza-CE. Brasil CEP: 60.714.903. Fone: 055.85.31019940. E-mail: felipegerhard.rns@gmail.com

2 Mestrando em Administração de Empresas. Universidade Estadual do Ceará. E-mail: lucaslfsouza@gmail.com

3 Doutora em Economia. Profa Adjunta do Curso de Administração de Empresas da Universidade Estadual do Ceará. E-mail: veronica.penaloza@uece.br

4 Mestrando em Administração de Empresas. Universidade Estadual do Ceará. E-mail: alexander_ brasil@yahoo.com.br 


\section{Abstract}

The performance of a retail market store is influenced, largely, by factors that perform a role in the costumer's rational decision making. However, several studies in small retails related an hedonic characteristic about consumer's behavior in these environments. Therefore, with the purpose to expand the comprehension about the consumer's experience in the small retails, this research proposes, as the main objective, analyze the consumer's buying behavior in the context of the hedonic and utilitarian dimensions. Besides, the study also identifies the main reasons which make a client go into a small retail. To achieve these objectives, a descriptive quantitative research was conducted, carried out through the application of a survey and the use of exploratory factor analysis. The findings of this research revealed that does not make sense segregate costumer's utilitarian and hedonic necessities once both are important in the costumer's buying decision making. Furthermore, was observed that the care service could transcend his simple functional utility and maximize the client's buying experience.

Keywords: Small Retail. Hedonic Consumption. Utilitarian Consumption.

\section{Introdução}

O desempenho de um estabelecimento varejista depende, em grande parte, de fatores capazes de desenvolver um papel racional no processo decisório de seus clientes (JONES; REYNOLDS; ARNOLD, 2006; HERNANDEZ, 2009; SAMPAIO et al., 2009). Todavia, segundo Luppe e Angelo (2010), o modelo racional das decisões de consumo no varejo pontua como os principais fatores na escolha do local de compra pelo consumidor: o preço, a proximidade, a utilidade da cartela de produtos e o atendimento básico. Tal abordagem revela um posicionamento utilitário de consumo, no qual se ignora qualquer limitação na capacidade de processamento de informação das pessoas.

Procurando aprofundar o conhecimento na área, diversos estudos em pequenos varejos buscaram relacionar o comportamento do consumidor nesses ambientes ao caráter de compra hedônico (e.g. SHERMAN; MATHUR; SMITH, 1997; BAKER et al., 2002; GATTO, 2002; SAMPAIO et al., 2009; BAGDARE; JAIN, 2012). Tais estudos reconhecem a presença de características complementares à utilidade 
funcional ao levantarem propostas de valor distintas ao segmento, tais como o atendimento diferenciado, a oferta de serviços e o ambiente de loja agradável (PARENTE; BARKI; KATO, 2007). De fato, o ambiente, segundo Sherman e Corty (1984) é ressaltado como um dos principais aspectos que deslocam os indivíduos do comportamento racionalmente orientado, pois incute incerteza nos consumidores, maximizando, desta maneira, a dimensão lúdica de compra. Dessa forma, o ato de comprar passaria a designar a ação de transcender aos limites físicos impostos pela matéria, dando ao indivíduo a possibilidade de atingir níveis elevados de experiência extracorpórea (ROCHA, 2005). Nesse caso, o ambiente de loja cumpre papel imprescindível, equiparando-se ao teatro, no qual o cliente atua como protagonista (GROVE; FISK, 1992; GATTO, 2002).

Entretanto, esses trabalhos avançam de maneira incipiente na temática e não são suficientemente claros em seus achados acerca da relação dos diversos elementos que compõe a complexa rede de variáveis concernentes ao comportamento de compra do consumidor em pequenos varejos (BAGDARE; JAIN, 2012). Com efeito, Sampaio et al. (2009) partilham do mesmo pensamento, evidenciando ainda que há grande limitação teórica concernente ao comportamento do consumidor de varejo quanto às dimensões de consumo hedônico e utilitário. Destarte, estudos que facultem novos aportes teóricos referentes ao comportamento do consumidor, e em particular àqueles do pequeno varejo, são requeridos, com o intuito de se lançar luz sobre os aspectos ainda pouco analisados dos valores de compra dos consumidores. Dessa forma, este artigo tem a seguinte questão de pesquisa: qual é o comportamento de compra dos consumidores de pequenos varejos pautando-se nas dimensões de consumo hedônico?

Assim, com o intuito de ampliar a compreensão sobre a experiência de compra do consumidor no pequeno varejo, o propósito central deste trabalho analisar o comportamento de compra dos consumidores pautando-se nas dimensões de consumo hedônico e utilitário. O estudo também objetiva perquirir as principais razões pelas quais os clientes frequentam um pequeno varejo, correlacionando as razões mencionadas aos principais preceitos e valores de consumo hedônico e utilitário 
de compra. Conhecer essas características é importante no sentido de permitir aos administradores deste tipo de estabelecimento adotar práticas positivas de gestão capazes de incrementar seu desempenho global, elevando as expectativas de sucesso do negócio em mercados em crescente competição e extremamente isomórficos.

Este trabalho estrutura-se em cinco seções além desta introdução. Apresenta-se, inicialmente, uma breve revisão de estudos relacionados aos valores de consumo hedônico e utilitário, com atenção especial ao pequeno varejo. Por conseguinte, serão tratados os principais aspectos metodológicos. Por fim, serão aferidos os resultados e apresentadas as considerações finais do estudo, bem como suas implicações gerenciais e recomendações para pesquisas futuras.

\section{Hedonismo e utilitarismo no contexto do pequeno varejo}

O comportamento humano é influenciado por diversos aspectos psicológicos que podem distorcer a identificação e a percepção dos fatos, fazendo com que o indivíduo, muitas vezes, incorra em decisões baseadas em julgamentos particulares e limitados, nos quais a racionalidade, prevista pela teoria da utilidade esperada pode não ser obedecida (KIMURA; BASSO; KRAUTER, 2006). Com efeito, o conceito de racionalidade limitada, desenvolvido por Simon (1957), explicita a ideia de que os indivíduos, invariavelmente, seriam capazes de potencializar a satisfação apenas parcialmente e nunca de forma completa, pois seria impossível levantar todos os dados possíveis no processo decisório. Deve-se tal fenômeno a limitações naturais na habilidade de discernimento do amálgama de informações disponíveis aos tomadores de decisão. Destarte, segundo o autor, seria inconcebível a ideia de que existam decisões inteiramente racionais.

Enquanto a teoria econômica clássica do consumo se baseava na busca da maximização da utilidade, não é mais esperado, por uma série de motivos comportamentais e de limites à racionalidade, que o processo decisório de compra de um indivíduo seja eficiente; mas, diferentemente, que atitudes não racionais impactem consistentemente 
o comportamento dos agentes econômicos (KAHNEMAN; TVERSKY, 1981). De fato, as teorias de consumo atuais estabelecem que algumas variáveis econômicas não podem ser descritas pelas condições de equilíbrio propostas pela teoria tradicional, tendo em vista que os agentes econômicos tomam decisões muitas vezes incompatíveis com atitudes baseadas em expectativas racionais (SHEFRIN, 2000).

Quanto à nova perspectiva irracional do processo de compra, Holbrook e Hirschman (1982) são considerados os precursores dos estudos sobre a dimensão hedônica de consumo. A ideia dos autores vai de encontro à abordagem tradicional, que mantém o foco sobre os aspectos utilitários da compra, ao concentrar-se nos aspectos subjetivos, emocionais e simbólicos do consumo. Corroborando os autores, Babin e Babin (2001) definem o hedonismo como um discurso voltado ao alcance da gratificação pessoal imediata na experiência de compra, pois, ao relacionar-se com o entretenimento, promove benesses emocionais e sociais ao consumidor. Destarte, segundo Rocha (2005), o caráter hedônico de consumo relaciona estreitamente o sucesso de compra à busca pela felicidade.

Por outro lado, a visão tradicional do consumo observa o fenômeno da compra somente através do prisma da objetividade e minimização dos riscos incorridos nesse processo (BATRA; AHTOLA, 1991). Tal discurso representa o valor utilitário de compra, uma vez que descreve o comportamento de consumo como funcional e racional, focado no alcance de resultados relativamente tangíveis da experiência de compra. O caráter utilitário do consumo relaciona intimamente o sucesso da compra à aquisição eficiente de um produto (BABIN; BABIN, 2001).

De acordo com Zorrilla (2002), essa concepção inicial, a qual aduzia a predominância de inclinações predominantemente utilitárias no consumo, passou a perder força gradativamente no comércio varejista, ao emergir a ideia de um comportamento de compra dual dentre os consumidores. Tal ideia é evidenciada por autores como Bardhi e Arnould (2005) e Lopes et al. (2010), cujas pesquisas salientam que o consumo utilitário e hedônico podem coexistir em uma experiência de compra, pois, mesmo tratando-se 
de valores diferentes, entende-se que eles não são excludentes entre si, apenas abordam características distintas. Outro fator que pode interferir nos valores de consumo são os produtos em si. Existem objetos que são estritamente utilitários; outros, unicamente hedônicos e alguns cujo valor de consumo causado pelo produto varia de pessoa para pessoa (GIL, 2008; OKADA, 2005.

Oara Levy e Weitz (2004, p. 6), varejo seria "um conjunto de atividades de negócio que adicionam valor aos produtos e serviços vendidos aos consumidores para seu uso pessoal ou familiar". Brito, Vieira e Espartel (2011), ao analisarem as definições hodiernas referentes ao varejo, caracterizam-no como um campo de grande abrangência ao afirmá-lo como um setor que inclui uma abundante diversidade de produtos e serviços, além de uma extensa cadeia de suprimentos e de inúmeros canais de distribuição. Ademais, observa-se uma extensa rede de relacionamentos entre varejistas e membros do canal através de uma infinidade de formas de marketing direto.

Aquiescendo à importância do campo delimitado pelo comércio varejista, Terra (2004) aduz que o setor é responsável por grande parte da comercialização de bens no Brasil. Já há muito, supermercados vêm expandindo os seus ramos de atuação e ampliando o sortimento dos produtos oferecidos; suas atividades, outrora restritas à comercialização de produtos alimentares e de higiene e limpeza, estão sendo estendidas para outros segmentos, como os relacionados a bens duráveis, semiduráveis e têxteis, entre outros (FÁVERO, 2004). Contudo, além da oferta de uma cartela de produtos ampla e diversificada, os estabelecimentos varejistas estão cada vez mais preocupados com o ambiente no interior da loja (GATTO, 2002). De acordo com Zorrilla (2002), o desenho de estabelecimentos comerciais e a criação de ambientes devem desenvolver-se ao ponto de proporcionar uma experiência de compra adequada ao consumidor, considerando-se ambas as dimensões: utilitária e hedônica. Os aspectos emocionais relacionados à compra, segundo o autor, não podem mais ser menosprezados pelos estabelecimentos varejistas, pois representam uma característica contundente no processo de tomada de decisão do 
cliente quanto à escolha do local de compra e dos produtos em oferta; tais fatores incutem valor agregado ao valor funcional oferecido inicialmente pelas empresas.

\subsection{Fatores utilitários pertinentes ao processo de compra no varejo}

A dimensão utilitária de consumo decorre de perspectivas orientadas à consecução de uma tarefa (BATRA; AHTOLA, 1991). Com efeito, o sucesso dessa dimensão de compra engloba aspectos mais tangíveis do consumo, como, por exemplo, encontrar com facilidade um produto que se procura (decorrente de um desenho funcional da loja), receber um serviço pretendido que seja necessário ao cliente ou adquirir uma informação útil pelos funcionários do estabelecimento (SAMPAIO et al., 2009). Diversos outros fatores estão associados à perspectiva utilitária do consumidor, orientada à realização de uma tarefa com eficiência. Limpeza, seleção de produtos, cortesia do pessoal, lotação e preço são apontados por Carpenter e Moore (2006) como os atributos mais importantes dentre os responsáveis por levar os consumidores a pequenos varejos. Ademais, de acordo com a pesquisa realizada por Hernandez (2009), as cinco principais razões que orientam os clientes à escolha de um determinado estabelecimento são: localização (23\%), preço (19\%), disponibilidade de estoque (13\%), conveniência (12\%) e hábito $(9 \%)$, ou seja, razões basicamente utilitárias, apesar de já serem esperadas respostas que não se relacionassem à dimensão hedônica de consumo, pois se tratam de razões inconscientes.

O preço relativo ao bem, além de se caracterizar como um dos fatores mais relevantes para a tomada de decisão do consumidor, também está delimitado pela dimensão utilitária de consumo (LUPPE; ANGELO, 2010). O fator está fortemente relacionado à escolha do local de compra, representando um dos principais parâmetros de comparação e avaliação entre estabelecimentos. Ademais, de acordo com Jones, Reynolds e Arnold (2006), aliado ao preço, varejistas têm há muito focado em disponibilizar uma grande variedade e sortimento de 
marcas e produtos como uma estratégia para atender as necessidades específicas de determinados nichos de mercado. $O$ fator variedade, segundo os autores, associa-se à dimensão utilitária de consumo por auxiliar na consecução de uma compra funcional e objetiva. Possuir uma boa variedade, aliada à disponibilidade imediata dos produtos oferecidos, acrescentam os autores, é o limiar mínimo para a competição.

Além do preço e da variedade, segundo Parente e Kato (2001), o desempenho de um estabelecimento varejista também depende grandemente de sua localização, pois a maior parte de suas vendas decorre de clientes que moram dentro de uma área geográfica relativamente pequena em torno da loja. Hamilton (2003), ao tratar especificamente do contexto de pequenas empresas, corrobora a acepção de Parente e Kato (2001) ao demonstrar que a estratégia de localização é um dos principais diferenciais do pequeno varejo, pois permite à empresa um melhor relacionamento com seus consumidores. $\mathrm{O}$ fator proximidade física está fortemente atrelado, de acordo com Applebaum (1966), um dos pioneiros a identificar a área de influência de supermercados por meio da técnica de mapeamento de clientes, à eficiência na consecução da atividade de compra; logo, pertence à dimensão utilitária de consumo. Destarte, ao ratificar os estudos de Applebaum (1966), Parente e Kato (2001) aduzem não prescindir conhecer os clientes de sua área de influência, para que seja possível oferecer-lhes produtos e serviços que atendam de fato as suas principais necessidades.

\subsection{Fatores hedônicos pertinentes ao processo de compra no varejo}

A compra no varejo também pode gerar valor a partir de uma experiência na forma de gratificação pessoal, englobando aspectos mais intangíveis e emocionais (BAGDARE; JAIN, 2012). Tais aspectos estariam delimitados no campo das experiências de compra hedônicas, capazes de proporcionar ao consumidor algo a mais do que a simples utilidade oferecida pelo produto (BATRA; AHTOLA, 1991). 
A sobrevivência no competitivo ambiente de varejo atual, aliada às nuances da conjectura econômica, requer mais do que simplesmente preços baixos e produtos inovadores (GREWAL; LEVY; KUMAR, 2009; NUTTAVUTHISIT, 2014). Verhoef et al. (2009) afirmam que criar experiência de compra superior parece ser um dos objetivos centrais do ambiente de varejo atual. Com efeito, Peñaloza, Quezado e Gordiano (2011) evidenciam que o valor de compra hedônico é predominante entre os consumidores do pequeno varejo de vestuário. Grewal e Levy e Kumar (2009) afirmam ser fundamental focar nas experiências de compra dos clientes para competir eficientemente, pois criar uma distinta experiência de compra no consumidor prove enormes valores econômicos às empresas (PINE; GILMORE, 1999). Para Grewal, Levy e Kumar (2009), a experiência de consumo inclui todo ponto de contato com o qual o consumidor interage com uma companhia, produto ou serviço, o qual provoque uma reação. Essa experiência, de acordo com Gentile, Spiller e Noci (2007), é estritamente pessoal e implica em envolvimento do consumidor em diferentes níveis, tais como racional, emocional, sensorial, físico e espiritual. Ademais, Verhoef et al. (2009) entendem que a experiência de consumo engloba a interação total do consumidor à empresa, incluindo as fases de procura, compra, consumo e pós-venda, podendo incluir também múltiplos canais de varejo.

O ambiente de venda cumpre papel imprescindível para a valoração do produto oferecido pela empresa, pois estimula a experiência de compra por parte dos clientes (GROVE; FISK, 1992; GATTO, 2002; NUTTAVUTHISIT, 2014). Ele é caracterizado, segundo Gatto (2002), por uma série de componentes materiais e imateriais que consentem em instaurar uma sólida e duradoura relação com o cliente. O ambiente de venda, chamado de atmosfera da loja por Feijó e Botelho (2012), está fortemente associado à ampliação da experiência de consumo. Para os autores, o efeito de fatores de merchandising, tais como layout dos setores da loja, comunicação, disposição do imobiliário, espaço de circulação e localização, volume, localização das linhas de produtos, bem como o posicionamento e combinação de cores dos itens na prateleira, são extremamente relevantes à estruturação da atmosfera da loja, pois 
são capazes de proporcionar maiores valores hedônicos de compra aos clientes, sem desconsiderar o valor funcional, incorrendo em aumento de receita à loja que se dispõe a otimizar esses fatores.

Da mesma forma, Parente, Barki e Kato (2007) indicam que sensações de bem-estar podem ser despertadas a partir da combinação de fatores como organização, ambiente, variedade e sortimento das mercadorias em exposição, contanto que adequadamente trabalhados. Segundo os autores, devido ao eminente potencial em influenciar a atitude do consumidor frente à companhia, a combinação desses vetores é uma poderosa estratégia para a formação ou modificação de valores e símbolos. Sampaio et al. (2009) complementam as afirmações dos autores ao porem em evidência o impacto de fatores visuais de design sobre a percepção de valor por parte dos clientes de um ponto de venda com autosserviço. Para o autor, o valor hedônico se manifestaria através da vontade de sentir-se em casa, quando frequentam pontos de venda com autosserviço. Vale ressaltar, contudo, que, além dos fatores mencionados, um conceito clássico de atmosfera de loja, proposto por Eroglu e Machleit (1989), coloca em evidência a importância, além do relacionamento com outros clientes no ambiente de loja, do contato do consumidor com os funcionários da empresa; tais conclusões são corroboradas por Khare (2013), que destaca o comportamento dos empregados e as relações sociais facultadas pela atmosfera da empresa na manutenção da qualidade em pequenos varejos. Confirmando a afirmação dos autores, Tsa, Tsa e Chang (2010) concluem que os consumidores pagam mais pelos serviços do que propriamente pelos produtos; aduzem ainda que os serviços se tornam fatores geradores de lealdade.

Entretanto, de acordo com Grewal, Levy e Kumar (2009) e Biamiatzi e Kirchmaier (2014), para se amplificar a experiência superior de compra, bem como visitas mais frequentes à loja e maiores lucros, a empresa deve dirigir atenção tanto a fatores hedônicos como utilitários de consumo, como: promoção, preço, merchandising, cadeia de abastecimento e localização. Os ambientes e desenhos, para Zorrilla (2002), devem ser pensados com o intuito de proporcionar tanto utilidade 
e prazer. Corroborando os autores, Sampaio et al. (2009) sugerem que sejam atendidas, primeiramente, todas as necessidades relacionadas aos valores utilitários do consumidor, pois, do contrário, afetar-se-ia negativamente a percepção de valores hedônicos. Yim et al. (2014), ademais, evidenciam que estímulos à motivação hedônica aumentam as vendas em ambientes utilitários. Coadunando as acepções supracitadas, Jones, Reynolds e Arnold (2006) comprovaram que tanto os valores hedônicos como os utilitários influenciam positivamente na satisfação do consumidor em ambientes de varejo.

Dessa forma, infere-se que os fatores utilitários são os predominantes no valor de compra de um pequeno varejo, uma vez que trabalha principalmente com bens de primeira necessidade. Entretanto dado o exposto acima, sabe-se que os fatores hedônicos também estão presentes no valor de compra desses ambientes. Destarte, o objetivo deste estudo é analisar o comportamento dos consumidores no ambiente de pequeno varejo, pautando-se na teoria hedônico e utilitário de consumo. Pretende-se também investigar as principais razões que orientam o consumidor na escolha do local de compra. Cumpre salientar que o foco do trabalho é conhecer o valor de consumo vinculado ao ambiente e que não será analisado o valor de consumo causado pelos produtos, como aduzem Gil (2008) e Okada (2005).

\section{Procedimentos metodológicos}

A pesquisa quantitativa, realizada em forma de survey descritivo, pretendeu analisar o valor de compra dos consumidores de um pequeno varejo, se hedônico e/ou utilitário, e obter informações sobre o perfil do consumidor. $\mathrm{O}$ estudo foi realizado em um pequeno varejo situado na periferia da cidade de Fortaleza. O comércio é composto por dois sócios familiares, que também trabalham nas atividades operacionais da empresa, e seis funcionários que se dividem no horário de funcionamento da empresa, das $6 \mathrm{~h}$ às $20 \mathrm{~h}$, de segunda a sábado, e aos domingos, das $8 \mathrm{~h}$ às $12 \mathrm{~h}$. O estabelecimento já é bem conhecido na região por ter mais de 10 anos de funcionamento, porém, nesse ínterim, houve troca 
de proprietários. Os atuais donos do estabelecimento adquiriram-no há cerca de três anos.

O estudo pesquisou uma amostra de natureza não probabilística por conveniência (SCHIFFMAN; KANUK, 2000; BABBIE, 2003) de 227 indivíduos. Os questionários foram aplicados no decorrer de várias semanas, durante os meses de janeiro a março de 2013, entre $7 \mathrm{~h}$ e $18 \mathrm{~h}$, período de maior afluência de público. O tempo de resposta do questionário era de cerca de oito minutos. Vale salientar, entretanto, que, após dois meses de pesquisas, praticamente se alcançou o número total de clientes que realizavam suas compras no próprio estabelecimento e se dispunham a responder ao questionário. Não foram entrevistados os clientes que faziam seus pedidos por telefone. Ademais, os pesquisadores que inicialmente conheciam o local visitaram-no com anterioridade para sentir qual seria a melhor forma de realizar a pesquisa. No préteste, embora não se tenha constatado problemas com o questionário, observou-se que havia pouca receptividade das pessoas, pois muitas preferiam o local justamente para se evitar a demora nas filas. Tal reticência foi superada ao se comentar que era de rápida aplicação. Cumpre destacar que também foi obtida maior receptividade quando ele era respondido longe da atenção dos donos do estabelecimento.

Quanto à escala utilizada, observando-se a coexistência dos dois valores de compra, utilizou-se a escala de valor de compra criada por Babin, Darden e Griffin (1994), com o intuito de aferir a intensidade em que se apresentam no comportamento de compra dos consumidores do pequeno varejo. Optou-se pela utilização dessa escala como embasamento da pesquisa devido a sua ampla utilização no ambiente varejista (JONES; REYNOLDS; ARNOLD, 2006). Ademais, a pesquisa utiliza-se da escala adaptada por Lopes et al. (2010), por já haver sido replicada em outras oportunidades com consumidores brasileiros.

O instrumento de pesquisa foi composto por 3 partes. A primeira parte, com 13 questões, corresponde à escala de Lopes et al. (2010), adaptada de Babin, Darden e Griffin (1994), em escala de Likert de 11 pontos, variando de 0 (discordo totalmente) a 10 (concordo totalmente). 
A escala está formada por 13 itens, 7 variáveis hedônicas e 6 utilitárias, evidenciadas no Quadro 1.

Quadro 1 - Variáveis hedônicas e utilitárias do instrumento de pesquisa

\section{Variáveis Hedônicas}

H1 Eu me diverti fazendo esta compra.

H2 Eu fiz esta compra porque quis, e não por obrigação.

H3 Comparando com outras coisas que eu poderia ter feito, o tempo gasto comprando este produto foi muito mais agradável.

H4 Esqueci os meus problemas enquanto estive no mercadinho.

H5 Fazer esta compra foi uma verdadeira distração para mim.

H6 Estar no mercadinho foi um jeito muito agradável de passar o tempo.

$\mathrm{H} 7$ A busca por este produto me deu um grande prazer.

\section{Variáveis Utilitárias}

U1 Eu fui eficiente ao fazer esta compra.

U2 Eu gastei apenas o tempo necessário para fazer esta compra.

U3 Eu fiz esta compra com rapidez.

U4 Fazer esta compra foi como cumprir uma obrigação.

U5 Foi fácil fazer esta compra porque eu sabia exatamente o que eu queria comprar.

U6 O preço que paguei nesta compra compensou o tempo que gastei.

Fonte: Adaptação da escala de Babin, Darden e Griffin (1994), elaborada por Lopes et al. (2010, p.17).

Na segunda parte, solicitou-se aos respondentes que dissessem as três principais razões que os levavam ao estabelecimento em questão; não obrigatoriamente era necessário que se respondesse as três razões. Quanto à terceira parte, realizaram-se perguntas de caráter socioeconômico, para averiguar-se o perfil do consumidor quanto à renda, escolaridade, etc.

Os dados foram analisados com auxílio do software Statistical Package for the Social Sciences (SPSS) versão 18.0, módulos de estatística descritiva e análise fatorial exploratória. 


\section{Análise dos resultados}

Com o âmago de perscrutar o comportamento de compra dos consumidores, concernindo-se aos valores de compra hedônico e utilitário, realizou-se a análise dos resultados, haurindo-se também o perfil socioeconômico dos consumidores e as principais razões que os faziam escolher o mercadinho em detrimento de outros locais.

Responderam ao questionário, 227 pessoas, 129 homens (56,9\%) e 98 mulheres $(43,2 \%)$, com idades que flutuam entre 14 e 80 anos e média de 37 anos. Com relação à renda familiar mensal, medida em salários mínimos, $43,6 \%$ dos entrevistados declarou possuir uma renda de até 3 salários, sendo a média salarial de 5,85 salários. O quartil mais pobre tem uma renda de até 2 salários e o quartil mais rico renda superior a 5 salários.

Com relação ao grau de instrução, 12,8\% não tem ensino fundamental completo, $33,5 \%$ tem somente o ensino médio completo e $18,9 \%$ completou o ensino superior. O alto índice de pessoas com o ensino superior completo se deve ao fato de haver um órgão do governo estadual na proximidade. Ademais, um alto índice de clientes, 23,7\%, compra somente no estabelecimento pesquisado. Os demais $76,3 \%$ dos consumidores compram em outros lugares pelo fato de haver, principalmente, maior variedade, $37,1 \%$, e preços mais baixos, $15,6 \%$.

$\mathrm{Na}$ Tabela 1 mostram-se os resultados da análise fatorial exploratória da escala de valor de compra. Usando o critério de extração com base no valor próprio maior que 1 , a escala mostrou-se eficaz, dado que, ao se excluir os itens $\mathrm{H} 2$, U4 e U6, agrupou-se em 2 fatores. Foram eliminados os itens $\mathrm{H} 2$ e U4, como já havia ocorrido em trabalhos anteriores, por se agruparem isoladamente e explicarem um terceiro fator (LOPES et al., 2010); também foi eliminado o item U6, "O preço que paguei nesta compra compensou o tempo que gastei", pois se agrupou aos dois fatores originais, já que compensação pode estar relacionado a uma característica hedônica, enquanto tempo pode ser considerado utilitário. 
Tabela 1 - Matriz de Componentes Rotacionada - Valores de Compra

\begin{tabular}{|c|c|c|}
\hline \multirow{2}{*}{ Variáveis } & \multicolumn{2}{|c|}{ Fatores } \\
\hline & Hedônico & Utilitário \\
\hline H1. Eu me diverti fazendo esta compra; & 0,744 & \\
\hline $\begin{array}{l}\text { H3. Comparando com outras coisas que eu } \\
\text { poderia ter feito, o tempo gasto comprando este } \\
\text { produto foi muito mais agradável; }\end{array}$ & 0,726 & \\
\hline $\begin{array}{l}\text { H4. Esqueci os meus problemas enquanto estive } \\
\text { no Mercadinho; }\end{array}$ & 0,702 & \\
\hline $\begin{array}{l}\text { H5. Fazer esta compra foi uma verdadeira } \\
\text { distração para mim; }\end{array}$ & 0,848 & \\
\hline $\begin{array}{l}\text { H6. Estar no Mercadinho foi um jeito muito } \\
\text { agradável de passar o tempo; }\end{array}$ & 0,868 & \\
\hline $\begin{array}{l}\text { H7. A busca por este produto me deu um grande } \\
\text { prazer. }\end{array}$ & 0,787 & \\
\hline U1. Eu fui eficiente ao fazer esta compra; & & 0,664 \\
\hline $\begin{array}{l}\text { U2. Eu gastei apenas o tempo necessário para } \\
\text { fazer esta compra; }\end{array}$ & & 0,761 \\
\hline U3. Eu fiz esta compra com rapidez; & & 0,803 \\
\hline $\begin{array}{l}\text { U5. Foi fácil fazer esta compra porque eu sabia } \\
\text { exatamente o que eu queria comprar }\end{array}$ & & 0,782 \\
\hline Alpha de Cronbach & 0,876 & 0,754 \\
\hline
\end{tabular}

Fonte: Elaborada a partir dos dados levantados na pesquisa.

Nota: Extration Method: Principal Component Analysis.

Rotation Method: Varimax with Kaiser Normalization.

Como é possível observar por meio da análise da tabela, utilizandose a rotação Varimax, análise dos componentes principais como método de extração, e o critério de autovalores superiores a 1 (HAIR JR. et al., 2005), todos os itens apresentaram cargas fatoriais satisfatórias (HAIR JR. et al., 2006). Do mesmo modo, a comunalidade de todas as questões superou o índice mínimo exigido de 0,5 (HAIR JR. et al., 2006), com exceção da variável $\mathrm{H} 4$, que apresentou valor ligeiramente inferior ao indicador $(0,494)$. A matriz anti-imagem também revelou valores satisfatórios para todas as variáveis. Quanto ao índice KMO $(0,852)$ e 
o teste de esferacidade de Bartlett $(p=0,000)$, a estrutura erigida pela análise apresentou valores satisfatórios (HAIR JR. et al., 2005).

Os dois fatores também apresentaram bons índices de confiabilidade atestada pelo Alpha de Cronbach; $\alpha=0,876$ para 0 primeiro fator, que representa o valor de compra hedônico e $\alpha=0,754$ para o segundo fator, que representa o valor de compra utilitário. Em conjunto, os dois fatores explicaram $61,37 \%$ da variância total, como é visualizado na Tabela 2, a seguir.

Tabela 2 - Variância Total Explicada

\begin{tabular}{|c|c|c|c|c|c|c|c|c|c|}
\hline \multirow{2}{*}{ Fator } & \multicolumn{3}{|c|}{ Autovalores Iniciais } & \multicolumn{3}{|c|}{$\begin{array}{l}\text { Extração da Soma dos } \\
\text { Quadrados das Cargas }\end{array}$} & \multicolumn{3}{|c|}{$\begin{array}{l}\text { Rotação da Soma dos } \\
\text { Quadrados das Cargas }\end{array}$} \\
\hline & Total & $\begin{array}{c}\text { Variância } \\
(\%)\end{array}$ & $\begin{array}{c}\text { Acumulado } \\
(\%)\end{array}$ & Total & $\begin{array}{c}\text { Variância } \\
(\%)\end{array}$ & $\begin{array}{c}\text { Acumulado } \\
(\%)\end{array}$ & Total & $\begin{array}{c}\text { Variância } \\
(\%)\end{array}$ & $\begin{array}{l}\text { Acumulado } \\
(\%)\end{array}$ \\
\hline 1 & 4,161 & 41,611 & 41,611 & 4,161 & 41,611 & 41,611 & 3,742 & 37,423 & 37,423 \\
\hline 2 & 1,977 & 19,765 & 61,377 & 1,977 & 19,765 & 61,377 & 2,395 & 23,954 & 61,377 \\
\hline 3 & 0,776 & 7,757 & 69,133 & & & & & & \\
\hline 4 & 0,659 & 6,594 & 75,727 & & & & & & \\
\hline 5 & 0,549 & 5,486 & 81,212 & & & & & & \\
\hline 6 & 0,508 & 5,085 & 86,297 & & & & & & \\
\hline 7 & 0,427 & 4,275 & 90,572 & & & & & & \\
\hline 8 & 0,403 & 4,029 & 94,601 & & & & & & \\
\hline 9 & 0,345 & 3,454 & 98,055 & & & & & & \\
\hline 10 & 0,195 & 1,945 & 100,000 & & & & & & \\
\hline
\end{tabular}

Fonte: Elaborada a partir dos dados levantados na pesquisa.

Nota: Método de extração: análise dos componentes principais.

Com base no exame das tabelas, é possível constatar que o fator mais relevante para a análise é o valor de compra hedônico, uma vez que representa $41,61 \%$ da variância total explicada. O valor do compra utilitário, por sua vez, explica $19,76 \%$ da variância, caracterizando-se como o segundo fator mais relevante da análise. Quanto aos demais fatores, observa-se que nenhum dos componentes alcançou um autovalor superior a 1 .

Por conseguinte, utilizando-se os escores fatoriais individuais, foram calculadas as diferenças entre os valores de compra hedônicos e utilitários para cada respondente. Tal procedimento foi realizado por 
Peñaloza, Quezado e Gordiano (2011), em um contexto similar ao desta pesquisa. Deve-se destacar que a importância da técnica reside no fato de se poder demonstrar com clareza a diferença entre os valores de compra atingidos pelos entrevistados, indicando, ademais, se o indivíduo possui ou não algum valor preponderante.

Dessa forma, observa-se que em 46,26\% da população entrevistada predomina-se o valor de compra utilitário, contra 53,74\% de predominância do valor de compra hedônico. Tais resultados evidenciam uma tendência ligeiramente maior ao caráter de compra hedônico entre os consumidores. Logo após, foram analisados os indivíduos de acordo com a polaridade de suas cargas fatoriais, apresentadas na análise fatorial exploratória. A partir desse procedimento, obtiveram-se os seguintes grupos: consumidores predominantemente hedônicos $(21,59 \%)$, que possuem carga fatorial hedônica positiva, mas apresentaram um escore fatorial utilitário negativo; consumidores predominantemente utilitários $(24,67 \%)$, que alcançaram carga fatorial utilitária positiva e um escore fatorial hedônico negativo; e consumidores que não apresentaram predominância de um valor de compra sobre o outro $(53,74 \%)$.

Através da divisão realizada, é possível observar que, diferentemente da primeira análise, os consumidores com uma dimensão predominantemente utilitária, ou seja, aqueles que possuem um valor de compra marcadamente pragmático e objetivo estão em maior número do que os consumidores com um valor de compra marcadamente hedônico. Por fim, mais da metade dos consumidores $(53,74 \%)$ apresentou valores de compra tanto hedônicos quanto utilitários. Tais resultados corroboram as acepções levantadas por autores como Zorrilla (2002), Grewal, Levy e Kumar (2009), Sampaio et al. (2009) e Yim et al. (2014), ao ratificarem a importância de se dirigir a atenção às duas dimensões de compra para que se proporcione tanto utilidade e prazer no ambiente da loja.

Quanto às razões que levam as pessoas a irem ao estabelecimento, obtiveram-se 405 respostas, as quais foram agrupadas em 11 grupos, como podem ser observados na Tabela 3. 
Tabela 3 - Razões que levam os consumidores ao pequeno varejo

\begin{tabular}{|c|c|c|c|c|c|}
\hline Fator & $\begin{array}{l}\text { Valor de } \\
\text { Consumo }\end{array}$ & Total (\%) & $\begin{array}{l}\text { Consumidores } \\
\text { Hedônicos (\%) }\end{array}$ & $\begin{array}{l}\text { Consumidores } \\
\text { Utilitários (\%) }\end{array}$ & $\begin{array}{c}\text { Hedônico } \\
\text { e Utilitário } \\
(\%)\end{array}$ \\
\hline Proximidade & Utilitário & 33,1 & 30,4 & 40,4 & 30,6 \\
\hline Atendimento & Hedônico & 19,3 & 25,0 & 6,7 & 23,0 \\
\hline Preço & Utilitário & 13,8 & 12,0 & 14,4 & 14,4 \\
\hline Variedade & Utilitário & 8,4 & 8,6 & 12,5 & 6,2 \\
\hline Gosta & Hedônico & 6,4 & 7,6 & 1,9 & 8,1 \\
\hline Ambiente & Hedônico & 4,2 & 3,3 & 1,0 & 6,2 \\
\hline Rapidez & Utilitário & 4,2 & 4,3 & 7,7 & 2,4 \\
\hline $\begin{array}{l}\text { Entrega em } \\
\text { Domicílio }\end{array}$ & Utilitário & 3,7 & 3,3 & 4,8 & 3,3 \\
\hline Obrigação & Utilitário & 3,2 & 2,2 & 5,8 & 2,4 \\
\hline Amizade & Hedônico & 2,7 & 3,3 & 4,8 & 1,5 \\
\hline $\begin{array}{l}\text { Cartão de } \\
\text { Crédito }\end{array}$ & Utilitário & 1,0 & 0,0 & 0,0 & 1,9 \\
\hline \multicolumn{2}{|l|}{ Total } & 100,0 & 100,0 & 100,0 & 100,0 \\
\hline
\end{tabular}

Fonte: Elaborada a partir dos dados levantados na pesquisa.

As razões mencionadas se relacionam, principalmente, à dimensão utilitária de consumo, pois representam $67,4 \%$ do total de respostas, alcançado a partir do somatório das porcentagens dos seguintes fatores: proximidade, preço, variedade, rapidez, entrega em domicílio, obrigação e cartão de crédito. As razões levantadas relacionadas à dimensão essencialmente hedônica correspondem a $32,6 \%$ do total de respostas, alcançado a partir do somatório das porcentagens dos seguintes fatores: atendimento, gosta, ambiente e amizade. Os resultados obtidos ratificam as razões levantadas na pesquisa de Hernandez (2009).

A razão proximidade obteve o maior percentual de respostas, com $33,1 \%$ do total. Os resultados reforçam a ideia evidenciada por Hamilton (2003), que demonstra existir grande dependência do varejo de menor porte quanto à sua localização geográfica e, consequentemente, à sua área de influência. Observa-se ainda que o fator obteve 40,4\% das respostas dentre os consumidores essencialmente utilitários; alcançando 
também uma alta percentagem dentre os consumidores com valor de compra essencialmente hedônico $(30,4 \%)$. Dentre os consumidores que apresentaram ambos os valores de compra, a razão proximidade também foi citada sobremaneira $(30,6 \%)$.

A segunda resposta mais comumente falada foi atendimento, com $19,3 \%$ das respostas totais, fator definido como essencialmente utilitário pela literatura (SAMPAIO et al., 2009), por se relacionar unicamente a satisfação utilitária de uma necessidade de compra do consumidor. Contudo, corroborando a importância do relacionamento com o cliente na experiência de compra do consumidor, evidenciada por Eroglu e Machleit (1989), Carpenter e Moore (2006) e Khare (2013), a razão atendimento levantada na pesquisa transcende a ideia inicial de consecução de uma atividade utilitária por estar associada a características preponderantemente hedônicas. Observou-se que há não somente um tratamento diferenciado para cada cliente, mas um laço de amizade presente na relação cliente-empresa; tais constatações também foram confidenciadas pelos próprios clientes ao se aplicar os questionários. As acepções supracitadas podem ser constatadas comparando-se os valores apresentados pelo fator atendimento dos consumidores essencialmente hedônicos $(25,0 \%)$ com os consumidores predominantemente utilitários $(6,7 \%)$. A razão atendimento também alcançou uma alta percentagem dentre os consumidores que demonstraram ambos os valores de compra (23,0\%).

A terceira razão com maior número de repetições foi o preço $13,8 \%$ do total de respostas. A razão preço representa um valor utilitário ao relacionar-se com a realização de uma compra com eficiência. Contudo, o fator obteve percentagens similares dentre os consumidores essencialmente hedônicos $(12,0 \%)$, utilitários $(14,4 \%)$ e com os consumidores que apresentam ambos os valores (14,4\%). A reduzida menção do preço dentre os consumidores pesquisados vai de encontro ao resultado de diversas pesquisas que o apontam como o principal fator relacionado à escolha de um estabelecimento varejista.

Ademais, a razão variedade foi mencionada com mais veemência dentre os consumidores utilitários $-12,5 \%$ do total. Por outro lado, a 
razão gosta foi mencionada com mais ênfase pelos consumidores essencialmente hedônicos $(7,6 \%)$ e com ambos os valores de compra $(8,1 \%)$, alcançando um total de $6,4 \%$ das respostas. As demais razões apresentam maiores percentagens de acordo com os valores de compra na qual estão delimitadas. Entretanto, destaca-se a percentagem alcançada pela razão amizade, apresentando maiores valores dentre os consumidores essencialmente utilitários (4,8\%).

Faz-se mister observar, entretanto, as semelhanças e divergências entre os resultados obtidos nesta pesquisa e os auferidos por Hernandez (2009). Segundo o autor, o fator localização (23\%), como aqui observado, seria o principal influenciador, dentre os pontuados pelos entrevistados, na escolha do local de compra. Contudo, os fatores disponibilidade de estoque, conveniência e hábito, embora a importância com a qual foram citados, não foram mencionados nesta pesquisa. Da mesma forma, o fator preço não atingiu uma importância tão grande no presente escrutínio quanto à alcançada na pesquisa de Hernandez (2009). À posição do preço encontra-se o atendimento, fator sequer mencionado na pesquisa do autor.

\section{Considerações finais}

Com o propósito central de analisar o comportamento dos consumidores pautando-se nas dimensões de compra hedônica e utilitária, é possível afirmar que esta pesquisa alcançou os objetivos almejados. Destarte, levantando-se também as principais razões pelas quais se frequenta tais ambientes e correlacionando-as aos valores de compra estudados nesta análise, este trabalho contribui para a compreensão das experiências de compra dos consumidores, especialmente, de pequenos varejos.

Os resultados revelam que não ocorreu a predominância de um valor de compra dentre os clientes do estabelecimento varejista avaliado, pois tanto a dimensão de consumo hedônica quanto a utilitária se mostraram marcadamente presentes dentre a maioria dos indivíduos pesquisados. Os dados evidenciam que há uma presença significativa 
de três grandes grupos de consumo: clientes essencialmente hedônicos, clientes essencialmente utilitários e clientes com ambos os valores de compra destacados.

Quanto aos grupos de consumidores com características marcadamente hedônicas ou utilitárias, observa-se que há um equilíbrio na quantidade de clientes pertencentes a cada grupo. Contudo, vale ressaltar a importância do grupo no qual os dois valores de compra coexistem simultaneamente, pois representa a maior fração de clientes do estabelecimento; corroborando a visão contemporânea de consumo, que aquiesce um enfoque dual ao comportamento do consumidor. A existência de tal grupo ressalta a importância de se valorizar a experiência de compra dos clientes, ampliada através da sistematização dos elementos tangíveis e intangíveis do ambiente da loja, não olvidando, porém, dos fatores fundamentais que envolvem toda e qualquer decisão de compra, tais como preço, variedade de produtos, área de influência, dentre outros, relacionados à dimensão funcional de consumo.

Quanto às principais razões que levam as pessoas a irem ao estabelecimento varejista, vale ressaltar a destacada importância do atendimento nas respostas obtidas dos consumidores, variável pouco mencionada dentre os estudos voltados a pequenos varejos. Embora a proximidade tenha obtido o mais alto percentual de resposta dentre as razões levantadas, assim como apontado por grande parte da literatura versada ao tema, o atendimento, como confidenciado pelos próprios clientes, transcende a ideia inicial de consecução de uma atividade utilitária de consumo ao correlacionar o conceito a características preponderantemente hedônicas; ao contrário do que estudos anteriores apontam. O atendimento mencionado cumpre uma função social, pois se refere ao relacionamento pessoal, a níveis superiores ao da simples relação cliente-empresa, entre os clientes e os funcionários do estabelecimento. O conceito de atendimento para os funcionários da empresa, como observado pelos pesquisadores, consiste, principalmente, em conhecer e despender o máximo de atenção ao cliente. Dá-se a consecução da atividade através da orientação cuidadosa, tratamento cordial e sempre pelo nome, compra de produtos específicos para cada 
cliente e, sobretudo, criação de um vínculo de amizade, independente de qualquer orientação mercadológica. A razão amizade chegou mesmo a ser citada por alguns clientes do estabelecimento. Ademais, o fator preço também foi mencionado demasiadamente, contudo, o resultado mostra que, apesar de ser determinante para a escolha de um estabelecimento varejista, outras razões contribuem mais fortemente para atrair e manter o cliente.

Como contribuições teóricas adicionais, a pesquisa demonstra que a abordagem mais adequada para se examinar os valores de compra hedônicos e utilitários é tratá-los de forma complementar. As duas dimensões de consumo não são antagônicas, mas revelam características distintas presentes nos consumidores. Não prescinde, principalmente ao setor empresarial, a ciência dessa concepção, uma vez que permite um entendimento mais apropriado do comportamento de compra dos consumidores modernos.

Como limitação do estudo, tem-se o fato da coleta de dados ter sido realizada somente em um estabelecimento varejista, dado que há pouca receptividade dos donos de pequenos varejos em permitir pesquisas em suas lojas. $O$ estabelecimento pesquisa foi o único que aceitou participar do estudo. Embora o local se adéque aos objetivos da pesquisa, seriam necessárias outras empresas de pequeno porte para compor uma amostra mais fidedigna dos consumidores desses locais. Realizando-se uma pesquisa mais abrangente, se possível até mesmo em outras cidades ou regiões do país, poder-se-ia generalizar os resultados do estudo com maior propriedade para o setor de pequeno varejo.

Como indicação para pesquisas futuras, seria interessante focarse no aspecto social da relação entre empresa e cliente, pois, como foi possível constatar através do estudo, a transcendência de objetivos puramente econômicos cria um forte vínculo entre os funcionários da empresa e o cliente, possibilitando a criação de um bem-estar no ambiente de loja tanto para os consumidores quanto aos colaboradores. 


\section{Referências}

APPLEBAUM, W. Methods for determining store trade areas, marketing penetration and potential sales. Journal of Marketing Research, Chicago, v. 3, n. 2, p.127-141, May, 1996.

BABBIE, E. Métodos de Pesquisas de Survey. Belo Horizonte: UFMG, 2003.

BABIN, B. J.; BABIN, L. Seeking something different? A model of schema typicality, consumer affect, purchase intentions and perceived shopping value. Journal of Business Research, Melbourne, v. 54, n. 2, p. 89-96, November, 2001.

BABIN, B. J.; DARDEN, W. R.; GRIFFIN, M. Work and/or Fun: Measuring Hedonic and Utilitarian Shopping Value. The Journal of Consumer Research, Chicago, v. 20, n. 4, p. 644-656, March, 1994.

BAGDARE, S.; JAIN, R. Measuring retail customer experience. International Journal of Retail \& Distribution Management, Leeds, v. 41, n. 10, p. 790-804, August, 2013.

BAKER, J. et al. The influence of multiple store environment cues on perceived merchandise value and patronage intentions. Journal of Marketing, Chicago, v. 66, n. 2, p. 120-141, April, 2002.

BAMIATZI, V. C.; KIRCHMAIER, T. Strategies for superior performance under adverse conditions: A focus on small and medium-sized highgrowth firms. International Small Business Journal, Thousand Oaks, v. 32, n. 3, p. 259-284, May, 2014.

BARDHI, F.; ARNOULD, E. Thrift shopping: combining utilitarian thrift and hedonic benefits. Journal of Consumer Behavior, Massachustets, v. 4, n. 4, p. 223-233, June, 2005.

BATRA, R.; AHTOLA, O. Measuring the hedonic and utilitarian sources of consumer attitudes. Marketing Letters, New York, v. 2, n.2, p. 159170, April, 1991. 
BRITO, E. P.; VIEIRA, V. A.; ESPARTEL; L. B. A pesquisa na área do varejo: reflexões e provocações. RAE - Revista de Administração de Empresas, São Paulo, v. 51, n. 6, p. 522-527, Nov/Dez, 2011.

CARPENTER, J. M.; MOORE, M. Consumer demographics, store attributes, and retail format choice in the US grocery market. International Journal of Retail \& Distribution Management, Leeds, v. 34, n. 6, p. 434-452, June, 2006.

EROGLU, S. A.; MACHLEIT, K. A. Effects of Individual and ProductSpecific Variables on Utilising Country of Origin as a Product Quality Cue. International Marketing Review, Leeds, v. 6, n. 6, p. 27-52, Nov/ Dec, 1989.

FÁVERO, L. P. Atuação em Tempos de Crise e Competitividade Acirrada. São Paulo: Programa de Administração de Varejo (FIA-FEA/ USP), 2004.

FEIJÓ, F. R.; BOTELHO, D. Efeito dos fatores de merchandising nas vendas do varejo. RAE - Revista de Administração de Empresas, São Paulo, v. 52, n. 6, p. 628-642, Nov/Dez, 2012.

GATTO, S. L'atmosfera del punto vendita quale strumento di differenziazione dell'insegna: una verifica empìrica delgli effetti della variabile olfativa. In: CONGRESSO INTERNAZIONALE "LE TENDENZE DEL MARKETING”, 2002, Venezia. Anais... Venezia: Università Ca' Foscari Venezia, novembre, 2002, p. 1-25.

GENTILE, C., SPILLER, N.; NOCI, G. How to Sustain the Customer Experience: An Overview of Experience Components that Cocreate Value with the Customer. European Management Journal, Brussels, v. 25. n. 5, p. 395-410, October, 2007.

GILL, T. Convergent products: What functionalities add more value to the base? Journal of Marketing, Chicago, v. 72, n. 2, p. 46-62, March, 2008. 
GREWAL, D.; LEVY, M.; KUMAR, V. Customer Experience Management in Retailing: An Organizing Framework. Journal of Retailing, Amsterdam, v. 85, n. 1, p. 1-14, March, 2009.

GROVE, S. L.; FISK, R. P. The Service Experience as Theater. Advances in Consumer Research, Duluth, v. 19, n. 1, p. 455-461, January, 1992.

HAIR JR. J. F. et al. Análise Multivariada de Dados. 5. ed. Porto Alegre: Bookman, 2005.

HERNADEZ, J. M. Foi Bom Para Você? Uma Comparação Do Valor Hedônico De Compras Feitas Em Diferentes Tipos De Varejistas. RAM - Revista De Administração Mackenzie, São Paulo, v. 10, n. 2, p. 1130, Mar./Abr., 2009.

HOLBROOK, M. B.; HIRSCHMAN, E. C. The Experiential Aspects of Consumption: Consumer Fantasies, Feelings, and Fun. The Journal of Consumer Research, Chicago, v. 9, n. 2, p. 132-140, September, 1982. JONES, M. A.; REYNOLDS, K. E.; ARNOLD, M. J. Hedonic and utilitarian shopping value: Investigating differential effects on retail outcomes. Journal of Business Research, Amsterdam, v. 59, n. 9, p. 974-981, September, 2006.

KAHNEMAN, D.; TVERSKY, A. The framing of decisions and psychology of choice. Science, New York, v. 211, n. 4481, p. 453-458, January, 1981.

KHARE, A. Retail service quality in small retail sector: the Indian experience. Facilities, Bingley, v. 31, n. 5/6, p. 208-222, Set./Out., 2013. KIMURA, H.; BASSO, L. F. C; KRAUTER, E. Paradoxos em finanças: teoria moderna versus finanças comportamentais. RAE - Revista de Administração de Empresas, São Paulo, v. 46, n. 1, p. 41-58, Jan./ Mar., 2006.

LEVY, M; WEITZ, B. A. Retailing management. Boston: McGraw-Hill, 2004.

LOPES, E. et al. Valores de compra hedônico e utilitário: duas aplicações no varejo especializado. In: ENCONTRO NACIONAL DA 
ASSOCIAÇÃO NACIONAL DOS PROGRAMAS DE PÓS-GRADUAÇÃO EM ADMINISTRAÇÃO, 34. 2010, Rio de Janeiro. Anais. Rio de Janeiro: ANPAD, 2010, p. 1-17.

LUPPE, M. R.; ANGELO, C. F. As decisões de consumo e a heurística da ancoragem: uma análise da racionalidade do processo de escolha. RAM - Revista de Administração Mackenzie, São Paulo, v. 11, n. 6, p. 82-106, Nov./Dec., 2010.

NUTTAVUTHISIT, K. How consumers as aesthetic subjects co-create the aesthetic experience of the retail environment. Journal of Retailing \& Consumer Services, Amsterdm, v. 21, n. 4, p. 432-437, July, 2014.

OKADA, E. M. Justification effeects on consumer choice of hedonic and utilitarian goods. Journal of Marketing Research, Chicago, v. 42, n. 1, p. 43-53, February, 2005.

PARENTE, J. G.; BARKI, E.; KATO, H. T. Estratégias de Marketing para o Varejo na Baixa Renda. In: ENCONTRO NACIONAL DAASSOCIAÇÃO NACIONAL DOS PROGRAMAS DE PÓS-GRADUAÇÃO EM ADMINISTRAÇÃO, 31. 2007, Rio de Janeiro. Anais... Rio de Janeiro: ANPAD, 2007, p. 1-14.

PARENTE, J. G.; KATO, H. T. Área de influência: um estudo no varejo de supermercados. RAE - Revista de Administração de Empresas, São Paulo, v. 41, n. 2, p. 46-53, abr./jun., 2001.

PEÑALOZA, V.; QUEZADO, I.; GORDIANO, E. Consumo Utilitario y Consumo Hedónico en el Beco da Poeira. In: ASAMBLEA ANUAL DE CLADEA, 46. 2011, San Juan, Anales... San Juan, Porto Rico: Asamblea Anual de CLADEA, 2011, p. 1-16.

PINE, J. P.; GILMORE, J. H. The Experience Economy. Boston: Harvard Business School Press, 1999.

ROCHA, E. Culpa e Prazer: imagens do consumo na cultura de massa. Comunicação, Mídia e Consumo, São Paulo, v. 2, n. 3, p. 123-138, Março, 2005. 
SAMPAIO, C. et al. Fatores visuais de design e sua influência nos valores de compra do consumidor. Revista de Administração de Empresas (RAE), São Paulo, v. 49, n. 4, p. 373-386, Out./Dez., 2009.

SCHIFFMAN, L.; KANUK, L. Comportamento do consumidor. 6 ed. São Paulo: LTC, 2000.

SHEFRIN, H. M. Beyond Greed and Fear: Understanding Behavioral Finance and the Psychology of Investing. Boston, MA: Cambrid: Harvard Business School Press, 2000, 368 p.

SHERMAN, E; MATHUR, A; SMITH, R. B. Store environment and consumer purchase behavior: mediating role of consumer emotions. Psychology \& Marketing, Norwich, v. 14, n. 4, p. 361-378, July, 1997.

SHERMAN, S. J.; CORTY, E. Cognitive heuristics. In: WYER, R. S.; SRULL, T. Handbook of social cognition. New Jersey: Erlbaum, 1984.

SIMON, H. A. Models of man. New York: John Wiley and Sons, 1957.

TERRA, E. A. A. Classificação do Varejo: um estudo sobre diferentes abordagens. São Paulo: Programa de Administração de Varejo FIAFEA/USP, 2004.

TSA, M. T.; TSA, C. L.; CHANG, H. C. The effect of customer value, customer satisfaction, and switching costs on customer loyalty: an empirical study of hypermarkets in Taiwan. Social behavior and personality, Palmerston North, v. 38, n. 6, p. 729-740, July, 2010.

VERHOEF, P. C. et al. Customer Experience Creation: Determinants, Dynamics and Management Strategies. Journal of Retailing, Amsterdam, v. 85, n. 1, p. 31-41, March, 2009.

YIM, Mark Yi-Cheon. et al. Hedonic shopping motivation and co-shopper influence on utilitarian grocery shopping in superstores. Journal of the Academy of Marketing Science, Thousand Oaks, v. 42, n. 5, p. 528544, September, 2014. 
ZORRILLA, P. Nuevas tendencias en merchandising. Generar experiencias para conquistar emociones y fidelizar clientes. Distribución y Consumo, Madrid, v. 12, n. 65, p. 13-20, Septiembre/Octubre, 2002.

Artigo recebido em: 21/01/2014 Aprovado em: 13/06/2014 